Revista Signos

2009, 42(70)

$171-195$

\title{
La argumentación y las emociones en el debate televisivo
}

\author{
Ivonne Fuentes \\ Universidad de Playa Ancha \\ Chile
}

Resumen: Este artículo tiene como propósito entregar los resultados de una investigación en la que se analizó el discurso argumentativo del programa televisivo de debate: El Termómetro. El objetivo de la investigación es determinar los tipos de emociones presentes en los discursos argumentativos, el lugar que ocupan en el esquema argumental y cómo se relacionan dichas emociones con la temática del programa. Los procedimientos metodológicos se inscriben dentro de la Teoría Crítica y el Análisis del Discurso, siendo un estudio exploratorio y cualitativo. Los resultados muestran que las emociones son positivas o negativas de acuerdo a la carga emotiva del tema propuesto a través de una pregunta específica y de un título que permite al moderador guiar a los argumentadores hacia esos polos.

Palabras Clave: Argumentación, debate televisivo, emociones, análisis del discurso, topoi argumentativos.

Recibido: 23-V-2008 Aceptado: $5-1-2009$
Correspondencia: Ivonne Fuentes (ivefuentes@hotmail.com). Facultad de Humanidades, Universidad de Playa Ancha. Avenida Playa Ancha 850, Valparaíso, Chile. 


\title{
Argumentation and emotions in debates on television
}

\begin{abstract}
This article reports the results of a qualitative and exploratory study of the argumentative discourse employed in the TV talk show El Termómetro. The objective of this investigation is to identify the types of emotions expressed in the argumentative discourse being studied, their location in the argumentative plan, and how these emotions relate to the topic being discussed. The method derives from critical theory and discourse analysis. The findings show that emotions expressed while arguing can be positive or negative, depending on the emotional load of the theme proposed by the TV host in the form of a specific question and a given title, both of which guide the participants in the debate to be inclined to either of the poles.
\end{abstract}

Key Words: Argumentation, TV debate, emotions, discourse analysis, argumentative topoi.

\section{INTRODUCCIÓN}

Hoy en día no podemos desconocer la importancia que ha recobrado la argumentación en los más diversos ámbitos públicos y académicos. El clima social, tanto en el ámbito político, educativo como religioso, se constituye en debate. Pero, a pesar de tanto interés en la argumentación como medio para lograr la adhesión de una audiencia a través de la validación de ideas, falta aún mucho por conocer acerca de los mecanismos que la rigen. Desde la retórica clásica, se reconoce un sitial importante al pathos que consiste en emocionar (animos impellere) a la audiencia. Este aspecto requiere pensar el mensaje en función de su destinatario cuya adhesión se desea lograr.

En ese contexto, se trata de analizar el discurso argumentativo del programa televisivo de debate semanal El Termómetro, presentado durante el mes de septiembre de 2003, para determinar, específicamente, los tipos de emociones presentes en este discurso, qué lugar del esquema argumental ocupan y cómo se relacionan dichas emociones con la temática del programa.

En la argumentación, y particularmente en el debate televisivo, el tipo de interacción que será objeto de nuestro análisis contempla el estudio del pathos como uno de los ejes centrales, por cuanto las emociones son utilizadas en todos los discursos argumentativos con mayor o menor frecuencia. El principal objetivo de esta investigación es el estudio de las emociones a través de los topoi argumentativos y su relación con la temática del discurso.

Dentro de este marco, podemos señalar que nuestro estudio se inscribe en la Teoría Crítica y el Análisis del Discurso, considerando que el principal objetivo de este estudio es indagar en una realidad determinada y describir lo que sucede en el debate televisivo, poniendo el foco en la expresión o manifestación de las emociones. Optaremos por el paradigma interpretativo cuyo interés radica en el estudio de los significados de las acciones humanas y de la vida social para llegar a comprender e interpretar la realidad. 
A modo de síntesis, podemos señalar que el programa televisivo que conforma nuestro material de trabajo es interesante desde un punto de vista histórico, por cuanto refleja un regreso al formato de las prácticas argumentativas en la pantalla chica, pero con un estilo renovado, como consecuencia del reestablecimiento de la democracia en nuestro país. También, el corpus cobra importancia desde los estudios del discurso porque no solamente apela a la oralidad desde una perspectiva lingüística, sino también prosódica y contextual. El esquema propuesto por Soulages (2004) para el análisis de las imágenes nos parece pertinente y práctico para clasificarlas a través de los cuatro niveles, lo que permite recoger mayor información al momento de aplicar el análisis.

A continuación, se presenta una síntesis del rol de la oralidad en la comunicación televisiva y el imaginario socio-discursivo al cual se adscribe el debate como medio de comunicación de masas, para llegar a la revisión del debate televisivo como discurso argumentativo poniendo énfasis en el tratamiento de las emociones. Se da cuenta de las decisiones metodológicas tomadas en esta investigación para el tratamiento de las emociones, mencionando su caracterización y análisis en el corpus seleccionado. Se plantean algunos ejemplos para dar cuenta de los resultados obtenidos y las conclusiones.

\section{Marco teórico}

\subsection{La oralidad en la comunicación televisiva}

En una investigación como esta, que contempla un corpus oral, es importante tener en cuenta ciertas características de la oralidad que pueden significar interesantes aportes a la hora de analizar los datos. A continuación, sintetizaremos algunas de estas características:

- Los enunciados orales como producciones de lengua hablada, rara vez son productos terminados, pues sobre todo, en el uso conversacional, quedan de manifiesto las etapas de confección.

- En la oralidad se conservan todos los borradores o ensayos léxicos, puesto que es imposible eliminarlos, a diferencia de lo que sucede en la escritura.

- Los hablantes pueden comentar, en el mismo discurso que están produciendo, las dificultades que enfrentan al intentar elegir el léxico apropiado. Por ejemplo: cuando alguien dice "lo tengo en la punta de la lengua" o "no me salen las palabras".

- El interlocutor puede venir en auxilio de quien habla para ayudar o sugerir la palabra que se precisa.

- En la oralidad, un hablante puede volver atrás sobre un sintagma ya enunciado, ya sea para completarlo o para modificarlo. 
- Los titubeos y las respuestas erróneas están lejos de ser residuos que hay que desechar; por el contrario, son las vías de acceso al funcionamiento de operaciones cognitivas.

En la argumentación, y particularmente en el debate televisivo, en el tipo de interacción que fue objeto de nuestro análisis, se debe tener en cuenta los elementos de la oralidad mencionados, pues pueden llevarnos a una transcripción más exhaustiva del discurso y tal vez a un análisis más minucioso en el que deberemos considerar, además de lo lingüístico, elementos tan complejos como son: la prosodia, los elementos paraverbales, las imágenes que acompañan a cada discurso y los juegos de cámara que permiten marcar el turno de los hablantes, entre otras cosas.

\subsection{El imaginario socio-discursivo}

No debemos olvidar que todo acto de comunicación depende de un principio de regulación ligado a ciertas normas dictadas por cada grupo social. Según Soulages (1999), esta instancia que determina el conjunto de las producciones discursivas constituye el imaginario socio-discursivo de una colectividad. Este imaginario regula lo que se puede y no se puede decir en cada género discursivo, así como también el modo de configuración de cada una de estas variedades discursivas, creando las diversas operaciones de producción y recepción de mensajes. Se manifiesta en ciertas formas ritualizadas que permiten establecer correlaciones entre la manifestación semiológica de los hechos discursivos y los datos exteriores a ella (contexto). Dichas correlaciones revelan las normas que rigen los rituales de comunicación de cada uno de estos registros, pero también los tipos de contenidos a los que apelan (saberes, valores, o bien actitudes compartidas por cada colectividad social). Las restricciones mencionadas permiten, de ese modo, delimitar las fronteras de cada género discursivo.

Este principio de regulación atraviesa los tres espacios que distinguen Charaudeau y Maingueneau (2002): discursivo, interdiscursivo y situacional. Toda representación del mundo se realiza bajo la supervisión de la tercera instancia que delimita la pertinencia de lo que ha de ser la discursividad social para un grupo determinado. En este marco se desarrolla la comunicación televisiva. Es aquí donde juegan un rol importante los estudios que se hacen sobre la ejecución, el formato y el impacto que producen los programas televisivos, considerando sus distintos estilos y géneros.

Para introducirnos en el mundo de la televisión, es pertinente ubicarnos en su origen, recordando que se impone como el medio de comunicación masivo de mayor importancia, después de 1945, cuando finaliza la Segunda Guerra Mundial. Sin embargo, ya existían transmisiones experimentales desde 1926 en Inglaterra, Estados Unidos y Alemania. En este último país fue donde comenzaron las primeras emisiones regulares de televisión, según información extraída de la 
Universidad Nacional de San Luis, Argentina, a través de su sitio web www.usanluis.ar

La televisión es reconocida, según Santibáñez (2003), como una fuente inagotable de mensajes cuya finalidad es transmitir información, entretener y educar. Estos fines se consiguen a través de diversos tipos de programas, entre los cuales se considera el debate televisivo, objeto de nuestro estudio, como una forma de desarrollar el pensamiento crítico, aprender a argumentar y a respetar al otro brindándole un lugar importante a la tolerancia. Entre las décadas del '70 y '90, el espacio otorgado a este tipo de programas de discusión no tuvo gran desarrollo, marcado en un largo periodo por el Régimen Militar. Sin embargo, la vuelta a la democracia trajo consigo el surgimiento de programas como El Termómetro (que conforma nuestro corpus), Tolerancia Cero, entre otros, que vienen a llenar los espacios que estuvieron vacíos durante tantos años.

Según Soulages (1999), la televisión da un vuelco en la época contemporánea en relación a sus funciones y usos, pasando de ser "una ventana abierta al mundo" a "una televisión relacional"; de un medio pasivo, a un medio interactivo en el que el espectador manifiesta sus inquietudes y la televisión se amolda a sus gustos y preferencias. Desde esta última perspectiva es necesario agregar que existen múltiples formas de relación entre el medio (la televisión) y los destinatarios. Estas formas denominadas "pactos comunicacionales" (Soulages, 1999) regulan la producción de sentido de las cadenas de emisión que deben coincidir con la recepción del telespectador, atendiendo al sentido del medio televisivo, también llamado "televisión de la intimidad". A través del tiempo, los formatos han ido cambiando en la programación televisiva, según los cambios generacionales y económicos.

En el marco de esta investigación es perentorio establecer los parámetros de la comunicación televisiva como un género particular y complejo que no está reservado al dominio de una disciplina en particular. Siguiendo a Lochard y Soulages (1998), podemos decir que para definirla debemos situarnos dentro de estos tres grandes polos: el primero se refiere, principalmente, a la forma de definir lo televisivo, los parámetros técnicos que soportan el origen audiovisual. El segundo se refiere a los criterios y modalidades de difusión, a su carácter directo y a lo que hoy en día se denomina nuevo tipo de escritura audiovisual. $Y$ el tercero investiga las formas particulares de manifestación del discurso televisivo y las relaciones particulares que se producen con el espectador.

\subsection{Formato y estilo}

El 'formato' es un concepto de la programación televisiva que aparece como uno de los pilares esenciales de las lógicas mediáticas de la producción y de la difusión (Soulages, 2002). El formato se ha impuesto como uno de los instrumentos de regulación que asegura la interfaz entre una fórmula televisiva y un público determinado. Según las investigaciones realizadas por este 
investigador, los estilos son más cambiantes e inestables que los géneros televisivos. Desde el advenimiento de la cultura de masas, cada generación ha ido definiendo su identidad sociocultural a través de estilos determinados, recurriendo al consumo de una serie de producciones culturales singulares. Ritualmente, cada generación consume su música, su cine, sus programas de televisión, cuyas temáticas y formas adaptadas al gusto actual están, en el fondo, muy próximas a las generaciones anteriores, solo el estilo los aleja.

Cada estilo descansa en procedimientos y en formas de expresión que elaboran el ethos expresivo de toda producción cultural, susceptibles de actualizar "factores de activación" en comunidades de públicos diversos (como el decorado, la iluminación, el estilo de filmación, etc.). Pero esta actividad está lejos de ser aleatoria y mucho menos despreciable. La televisión es una práctica estética e industrial, inteligente y muy reflexiva. Este espectáculo estilístico se sustenta en una competencia estilística semiótica muy presente en el universo de la producción, aunque a menudo sea poco visible e ignorada por la elite culta. Por su parte, el estilo constituye el propio material del espectáculo, actualizando unas formas estéticas coreografiadas según un diseño visual intensamente reflejado por la cámara. Los productores pueden destacar, dentro de este conjunto, un sin fin de formas, una combinación que se cristalice a través de una fórmula propia en cada programa.

\subsection{Las imágenes}

No estamos ajenos al gran poder que ejerce la televisión sobre los telespectadores a través de una serie de imágenes, música, juego de cámaras que permiten poner en primer plano unos elementos por sobre otros.

El espectador mira la imagen desde su propia experiencia, desde su propia cultura y valores sociales y es desde esa perspectiva que cada imagen es comprensible por medio de algunas reglas culturales informales y adquiridas, pero no del todo codificadas. Soulages (2004) señala que es por esta razón que el saber de la imagen sigue siendo informal, abierto y muy difícil de circunscribir. Esta competencia semiótica se funda en las inferencias iniciadas por el mensaje visual, pero también por cálculos sugeridos por la situación de comunicación.

El significado de la imagen debe ser estudiado como una correspondencia entre el contenido sociocultural del objeto y su modo de representación, que es el producto de convenciones culturales y discursivas, como también de experiencias personales. La clave está dada por la situación y el contrato de comunicación, es decir, el contexto comunicativo permite al lector completar la representación fotográfica, dando un significado a la imagen de acuerdo a estándares culturales en la situación particular en la que se encuentra. 


\subsection{La argumentación}

La argumentación corresponde, siguiendo a Calsamiglia y Tusón (1999), a una práctica discursiva cuya función comunicativa es llevar, guiar al receptor para conseguir su adhesión.

Se sabe que el interés por la argumentación se vincula históricamente a la retórica, la oratoria y la dialéctica clásicas, como las tres disciplinas que formulan los principios y las técnicas de persuasión, sirviendo de base a los discursos institucionales y públicos (Calsamiglia \& Tusón, 1999).

Durante los siglos XII y XIII los debates eran tan corrientes como espectaculares. Según Cattani (2003), se les podía comparar con encuentros deportivos por su espíritu competitivo, recibiendo el nombre de disputa litigiosa. El mismo autor señala que la conducta competitiva se inspira en la lógica del nors tua, sita mea, (si uno vence, el otro pierde). Existen varios niveles de competencia que van desde el deseo de solucionar un conflicto, la simple divergencia, pasando por el desacuerdo, el conflicto hasta el antagonismo radical.

De acuerdo con la propuesta de Cattani (2003), la conducta competitiva se presenta como 'divergencia' que admite la coexistencia de opiniones distintas, mientras que el 'desacuerdo' supone una diferencia más seria y el 'conflicto' implica un final con vencedores y vencidos, en tanto que el 'antagonismo' se configura como una lucha continua.

La conducta colaboradora, por otro lado, se caracteriza por un espíritu del tipo "vence el uno, vence el otro". En este caso se busca una solución al conflicto, surgiendo, en condiciones ideales, un coloquio-diálogo en el que "uno busca a alguien que le ayude a dar 'luz' a la verdad" (Cattani, 2003).

\subsubsection{El debate televisivo como discurso argumentativo}

Plantin (1989) concibe la argumentación como una actividad racional, inserta en el lenguaje cotidiano, en la interacción comunicativa diaria; desde esta perspectiva, la actividad de argumentar consiste en dirigir un argumento a un interlocutor, es decir, una buena razón para que admita una conclusión, asegurando así un comportamiento adecuado por dicho interlocutor.

En el caso del programa seleccionado para nuestra investigación, teniendo en cuenta los antecedentes sobre el formato y los cambios de estilo, podemos ubicar los programas televisivos de debate, como El Termómetro, enmarcados en un estilo de debate que involucra a un conjunto de panelistas conducidos en tiempos y temas por un moderador, ubicado en el centro de la escena, que trata de mantener viva las controversias, una audiencia que se ubica detrás de los panelistas en un semicírculo desde el que son testigos del debate, pero sin derecho a participar; la escenografía también contempla una pantalla que proyecta imágenes relacionadas con el tema y un 
gráfico que da cuenta de las preferencias del telespectador frente a las dos posiciones adversas que se discuten al aire.

Al concebir el debate televisivo como un tipo de discurso argumentativo, nos vemos en la obligación de adoptar una propuesta particular de argumentación que se adecue a este tipo de discurso y nos permita un análisis del mismo; igual cosa sucede con las emociones y la puesta en imágenes. Por ello, se ha optado por la postura de Plantin (1989) que cumple, a nuestro juicio, con los requisitos teóricos y metodológicos propios de este tipo de estudio.

\subsection{Las emociones}

El estudio de las emociones cobra real importancia al ubicar el discurso argumentativo en un marco social, pues permite analizar el discurso destacando el lugar que le corresponde al pathos al interior de la argumentación cotidiana.

Según Lo Cascio (1998), el aspecto de valoración de los argumentos está vinculado al análisis y clasificación de los tipos de argumentación, su contenido y su relación con el éxito argumentativo, esto es, a su capacidad de persuasión, manipulación o incumplimiento de la ética argumentativa. Es el ángulo en que están en juego, principalmente, la cultura y los universos ideológicos de los protagonistas. En consecuencia, según este autor, el procedimiento de valoración se compone de dos fases: una, que concierne a la calidad del razonamiento y, por lo tanto, a la validez de los argumentos o de las reglas generales adoptadas para justificar el paso de una serie de datos a las conclusiones, tesis y opiniones propuestas, coherencia de la estructura, etc.; y otra, que corresponde a la calidad del comportamiento, las condiciones externas de conducta, es decir, la capacidad de juzgar cómo un acto argumentativo se desarrolla desde el punto de vista de la coherencia de los protagonistas, de la atmósfera, de las condiciones externas, de las emociones, etc.

Pondremos mayor atención en la segunda fase propuesta por Lo Cascio (1998) por tratarse de un marco referencial para las emociones, tema que constituye el objeto central de esta investigación. Los individuos intercambian enunciados y al hacerlo imprimen en ellos emociones y reflejan actitudes. Todos nuestros enunciados están impregnados de vida social, emotiva e ideológica que, en definitiva, es lo que corresponde simplemente a la vida cotidiana.

El tratamiento de las emociones nos parece esencial en la orientación global del discurso retórico cuyo fin es la persuasión. Desde la perspectiva de Plantin (1998) y, probablemente, desde Aristóteles, la retórica es concebida como una técnica del discurso orientada a poner en funcionamiento una acción, que puede ser tanto hacer pensar, como hacer decir, o bien, hacer hacer algo. 


\subsubsection{Las emociones en el discurso argumentativo}

Si analizamos nuestra vida, nuestro actuar, nos daremos cuenta de que a menudo actuamos desde la razón y los sentimientos sin hacer distingos conscientes. Intuir e incluso amar, no son actos completamente alógicos. Y, por su parte, los procesos que nos parecen absolutamente racionales, también están teñidos de sensibilidad.

Pero así como las emociones no ocuparon un sitial importante en la Filosofía a través de la historia, tampoco corrieron mejor suerte en el estudio de la argumentación, desde la Retórica clásica hasta nuestros días. En las teorías argumentativas contemporáneas, por ejemplo, el Tratado de Perelman y Olbrechts-Tyteca (1989) también se limita a oponer clásicamente la razón a las pasiones. Aquí la referencia exclusiva al ethos recuerda la definición antigua: la emoción no figura más que como pathos. Las pasiones son definidas sistemáticamente como el elemento irracional, obstáculo en la acción de la razón: el discurso pasional es un discurso figurado y degradado.

Similar posición en relación a la emoción plantea la nueva dialéctica o teoría pragmadialéctica de la argumentación que desarrolla una concepción del debate como método de resolución de diferencias de opinión. La discusión crítica es racional en la medida en que respeta un sistema de reglas; la emoción se ubica dentro de una teoría, en términos de falacias de la argumentación. El tema de la emoción es ejemplificado con violaciones a la regla 4: "Una parte solo puede defender su punto de vista presentando una argumentación que esté relacionada con ese punto de vista" (van Eemeren \& Grootendorst, 2002:223). En las violaciones de esta regla por parte del protagonista, en la etapa de la argumentación, van Eemeren y Grootendorst (2002:25) plantean que:

"La argumentación no se refiere al punto de vista en discusión (argumentación irrelevante). El punto de vista no se defiende por medio de una argumentación, sino empleando medios de persuasión no argumentativos (a) Manipulando las emociones de la audiencia; y (b) Enumerando las cualidades propias".

En cambio, Walton (1992), a pesar de situarse en el marco teórico de la pragmadialéctica, otorga un lugar a la emoción en el argumento, considerando la existencia de cuatro argumentos emocionales: ad baculum, ad misericordiam, ad hominem y ad populum; el valor racional de la apelación a una emoción es evaluado en función de un conjunto de principios posibles de interpretar como un contra-discurso dirigido a argumentaciones fundadas sobre esta emoción. Esto significa que aun cuando reconoce argumentos emocionales, estos tienen el estatus de falacias. 


\section{Marco metodológico}

El principal objetivo de esta investigación fue describir la expresión o manifestación de las emociones en el marco del debate televisivo. Optamos por el paradigma interpretativo cuyo interés radica en el estudio de los significados de las acciones humanas y de la vida social para llegar a comprender e interpretar la realidad. Los procedimientos metodológicos de nuestro estudio se inscriben en la Teoría Crítica y el Análisis del Discurso. Se trata de un análisis cualitativo, coherente con el paradigma interpretativo, y las ideas acerca de la construcción de la realidad.

La investigación se realizó a partir de 18 programas televisivos El Termómetro. De ellos seleccionamos cuatro, considerando que la temática de cada uno de ellos fuese distinta y enfocada por panelistas de distintos ámbitos: alcaldes, senadores, diputados, dirigentes políticos y deportivos (del fútbol), y periodistas.

\subsection{Programas y preguntas introductorias seleccionados}

- Violencia en los estadios ¿Se perdió la guerra contra las barras bravas? (35 minutos). DEPORTE.

- Crédito FF.AA. ¿Debe el Estado financiar a estudiantes de las FF.AA.? (20 minutos). CIVIL, MILITAR.

- Ley de alcoholes ¿Protección a los menores o atentado a la bohemia? (40 minutos). SERVICIO PÚBLICO.

- Prohibición de marchas ¿Atentado a la libertad de expresión o seguridad ciudadana? (40 minutos). POLÍTICO.

\subsection{Preguntas de investigación}

¿Qué tipo de emociones aparecen en el discurso propio del debate televisivo, como un tipo de discurso argumentativo?

¿Cuál es la relación entre el tipo de emoción, ya sea esta positiva o negativa, que aparece en el discurso y la temática de éste?

¿Qué tipo de topos aparecen con mayor frecuencia?

\subsection{Objetivos de la investigación}

- General:

- Analizar críticamente las emociones a través de los topoi argumentativos y su relación con la temática del discurso. 
- Específicos:

- Determinar el tipo de emociones presentes en el discurso argumentativo propio del debate.

- Determinar si estas emociones dependen de la temática del debate.

- Establecer qué tipo de topos son los que más se repiten en los argumentos que contemplan emociones.

\subsection{Metodología}

\subsubsection{Categorización de las imágenes}

En primer lugar, se procede a categorizar las imágenes en el corpus de trabajo. Es preciso considerar que las imágenes juegan un rol importante en la comunicación de emociones y para ello tomamos a Soulages (2004), quien propone una categorización de ellas en distintos niveles de organización, partiendo de un plano externo que contempla elementos plásticos para llegar a un plano interno, relacionado con lo discursivo y lo sociocultural:

- Nivel plástico: incluye las sustancias semióticas que constituyen el material visual, esto es, colores (cálidos y fríos), luz (suave o violenta), formas (curvas o rectas), texturas (cálidas, frías, duras). Los componentes visuales no son mecánicos sino dinámicos, no son estímulos independientes sino locales y producen un efecto global de sentido que afecta al sujeto observador.

- Nivel icónico: incluye las formas analógicas, los íconos; es la identificación de los objetos que corresponden a una competencia enciclopédica que, a su vez, descansa en la competencia perceptiva del espectador.

- Nivel discursivo: trata de la organización discursiva del mensaje, distinguiendo cuatro modos: 'presentativo', el que presenta un elemento aislado; 'descriptivo', en el que existe un universo en juego y aparece una situación en contexto; 'calificativo' de la acción, y 'narrativo': un personaje hace algo que le confiere una identidad que requiere una búsqueda. Este último corresponde al esquema narrativo clásico (presentación, nudo y desenlace).

- Nivel simbólico: incluye la configuración del imaginario social, relacionado con el tipo de discurso y la situación de comunicación en la que nos encontramos. En este caso, dentro del debate televisivo, es importante que las imágenes marquen el punto de conflicto, mostrando una u otra posición con un fuerte apego a las emociones. 


\subsubsection{Dimensiones discursivas}

En segundo lugar, debemos trabajar con las dimensiones discursivas. Para ello, seguimos a Plantin (1998) en su estudio de la argumentación en tres dimensiones discursivas: una dimensión 'textual', que contempla la organización de la materia argumentativa, principalmente, los tipos de argumentos y la forma de presentación; una dimensión 'interaccional', que considera diferentes procedimientos de armonización entre los interlocutores, es decir, las palabras por las cuales el locutor crea un ambiente propicio para desarrollar la argumentación y preparar a un interlocutor para que la reciba favorablemente; y, por último, una dimensión 'emocional', que contempla aquellos procedimientos que permiten a un locutor conseguir la simpatía, el asentimiento e idealmente la adhesión del auditorio.

\subsubsection{Tópicos de las emociones}

Un tercer momento se relaciona con los tópicos de las emociones y los argumentos. Por una parte, un argumento es un enunciado que contiene más de una "línea argumentativa" (Plantin, 1998). Y, por otra, los tópicos o topoi que se expresan en forma interrogativa:

T1: El evento ¿Qué? Corresponde a los contenidos emotivos del evento y se relaciona con las reglas retóricas de mimesis emocional; en otras palabras, de qué se trata el evento emotivo.

T2: Las personas afectadas ¿Quién? Este topo se refiere a las personas afectadas y es importante por cuanto la emoción varía de acuerdo a quien afecta el hecho. Por un lado, hay que considerar que ciertas personas despiertan más emociones que otras: la muerte de un niño afecta 'más' que la de un anciano; por otro lado, el mismo evento: 'ganarse el premio mayor de la lotería', no suscita los mismos sentimientos según si el afectado es 'un hombre famoso' o una 'familia de escasos recursos'.

T3: Las analogías ¿Cómo...? La importancia de la analogía en la producción de las emociones está muy bien expresada por el principio de Ungerer (1995) "uso metafórico ligado a los dominios estables de las emociones". En otras palabras, hay dominios especialmente 'sensibles', y mediante símiles o metáforas se puede hacer referencias a ellas.

T4: Tiempos ¿Cuándo? Esta pregunta nos lleva al modo de construcción temporal y aspectual de eventos, la exclusión o la inclusión dentro de la temporalidad subjetiva de la persona.

T5 Lugar ¿Dónde? ¿Dónde se produce el evento? ¿En un lugar emocionalmente marcado? Se relaciona con las técnicas retóricas de topografía. Hay lugares más asociados a emociones (cementerio, campo de batalla). En todo caso, mientras más cercano al interlocutor más tono afectivo tiene para él. 
T6: Cantidad ¿Cuánto? ¿Con qué intensidad? La dimensión o la magnitud del evento pueden tener estrecha relación con las emociones que despierta, así como la cantidad de personas involucradas o cualquier alusión a cantidad que despierte la sensibilidad en la audiencia.

T7: Causa/agente ¿Por qué? ¿Cuál es la causa, la razón, el motivo? Es interesante notar cómo el origen y variaciones de la emoción están vinculados a la imputación de responsabilidad, por ejemplo, las emociones en una situación determinada dependerán de si el accidente es una fatalidad o un acto deliberado.

T8: ¿Consecuencias? Este topo está relacionado con las predicciones que se pueden desprender de un evento. El proyectarse o señalar las consecuencias que se extraen a partir de un hecho puede desencadenar una serie de emociones.

T9: Conformidad/incompatibilidad con las normas de... ¿Normas? Este topo está vinculado a las normas o valores sociales establecidos culturalmente. Son aquellas normas reconocidas en la memoria colectiva y varían de una sociedad a otra.

T10: Posibilidad de control del evento por... ¿Control? Se refiere a los elementos explícitos en el argumento sobre lo cerca o lejos que se consideran los hechos, si es clara o difusa la presentación del hecho, y si es asertivo o no, convirtiéndose estas en posibilidades de control que dan cuenta desde la posición del enunciador de las emociones en potencia de acuerdo al compromiso que tiene con el hecho.

T11: ¿Cuál es la distancia entre... ¿Distancia de? ¿Qué grado de proximidad o de intimidad existe con el evento? Este topo explicita la focalización subjetiva de la producción de emociones, es decir, desde qué lugar o posición el argumentador presenta los hechos. Permite establecer el grado de compromiso que tiene con la argumentación planteada y si habla desde una postura personal o como representante de una colectividad.

T12: Es agradable o desagradable por ¿acuerdo, consentimiento? Este topo se ubica en la conclusión, equivale a la evaluación global del evento.

Cada uno de estos topoi sirvió de base para clasificar aquellos argumentos en los cuales estaban presentes las emociones de forma directa o indirecta. La pregunta retórica que introduce cada topo sirve de ayuda para orientarnos al momento de buscar la información y establecer el vínculo entre el evento y las emociones.

\subsubsection{Clasificación de las emociones y su relación con los argumentos}

Para determinar los topoi psicológicos posibles, es necesario construir paradigmas de designación, esto es, un conjunto de términos (sustantivos comunes o propios) y expresiones que usan 
los diferentes actores del discurso. La organización de un inventario sistemático para la designación de las emociones se puede llevar a cabo estableciendo los siguientes niveles:

- Designación directa de la emoción

Entenderemos por designación directa de la emoción la referencia a ella mediante un término específico. Para delimitar la clase de términos de sentimientos/emoción (sustantivos, verbos, adjetivos) utilizaremos las siguientes tres categorías:

(1) Nombre del sentimiento/emoción, aparece en contextos tales como: un sentimiento de + nombre de sentimiento = "un sentimiento de lealtad", entendiendo lealtad en primera instancia como valor y luego como sentimiento. Perelman y Olbrechts-Tyteca (1989) y van Eemeren y Grootendorst (2002) consideran que "lealtad" expresa una forma de "emoción positiva".

(2) Conjunto de derivados morfo-léxicos de cada sustantivo de base que expresa un sentimiento. Por ejemplo, a partir de odio se recupera odiar, rencoroso (en su relación con odio).

(3) Listas de vocabulario proporcionadas por psicólogos en torno a los conceptos "emoción" o "sentimiento" o extraídas de diccionarios de sinónimos. En este último caso, y para efectos de nuestra investigación, hemos recurrido al Diccionario de la Real Academia Española de la Lengua (www.rae.es) para establecer el listado de emociones que utilizaremos con las respectivas acepciones pertinentes al caso. Estas emociones coinciden, en su mayoría, con las propuestas de Russell, Lewicka y Niit (1992) y de Damasio (1998). 
Agrado: (De agradar) Afabilidad, modo agradable de tratar a las personas. Complacencia, voluntad o gusto.

Angustia: (Del lat. Angustia, angostura, dificultad) Aflicción, congoja, ansiedad. Temor opresivo sin causa precisa. Dolor o sufrimiento.

Aversión: (Del lat. Aversio, -onis) Rechazo o repugnancia frente a alguien o algo.

Bienestar: (De bien y estar) Estado de la persona en el que se le hace sensible el buen funcionamiento de su actividad somática y psíquica.

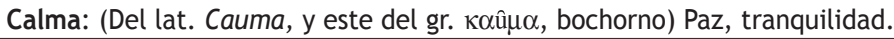

Celos: Celoso, sa (Del lat. Zelosus) Sospecha de que la persona amada mude su cariño. Recelo que alguien siente de que cualquier afecto o bien que disfrute o pretenda, llegue a ser alcanzado por otro.

Confianza: (De confiar) Esperanza firme que se tiene de alguien o algo. Ánimo, aliento, vigor para obrar.

Culpa: (Del lat. Culpa) Acción u omisión que provoca un sentimiento de responsabilidad por un daño causado.

Desagrado: (De desagradar) Disgusto, descontento. Expresión, en el trato o en el semblante, del disgusto que causa alguien o algo.

Desconfianza: Falta de confianza.

Disposición: (Del part. Irreg. De disponer, lat. Dispositus) Con ánimo favorable.

Empatía: Identificación mental y afectiva de un sujeto con el estado de ánimo de otro.

Fatiga: (De fatigar) Agitación duradera, cansancio, trabajo intenso y prolongado. Molestia ocasionada por un esfuerzo más o menos prolongado o por otras causas y que se manifiesta en la respiración frecuente o difícil.

Felicidad: (Del lat. Felicitas, -atis) Estado de ánimo que se complace en la posesión de un bien. Satisfacción, gusto, contento.

Frustración: (Del lat. Frustratio, -onis) Acción y efecto de frustrar. Privar a alguien de lo que esperaba. Ira: (Del lat. Ira) Pasión del alma, que causa indignación y enojo.

Malestar: (De mal y estar) Desazón, incomodidad indefinible.

Miedo: (Del lat. Metus) Perturbación angustiosa del ánimo por un riesgo o daño real o imaginario. Recelo o aprensión que alguien tiene de que le suceda algo contrario a lo que desea.

Molestia: (Del lat. Molestia) Enfado, fastidio, desazón o inquietud del ánimo.

Orgullo: (Del lat. Orgull) Arrogancia, vanidad, exceso de estimación propia, que a veces es disimulable por nacer de causas nobles y virtuosas.

Resentimiento: Resentirse. Tener sentimiento, pesar o enojo por algo.

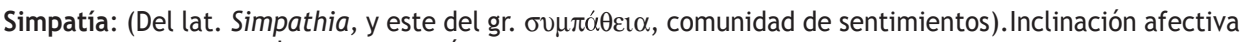
entre personas, generalmente espontánea y mutua.

Sorpresa: Acción y efecto de sorprender. Coger desprevenido.

Tensión: (Del lat. Tensio, -onis) Estado anímico de excitación, impaciencia, esfuerzo o exaltación.

Tristeza: (Del lat. Tristitia) Cualidad de triste. Adj. Afligido, apesadumbrado.

Verguienza: (Del lat. Verecundia) Turbación del ánimo, que suele encender el color del rostro, ocasionada por alguna falta cometida, o por alguna acción deshonrosa y humillante, propia o ajena.

Cuadro 1. Listado de emociones extraídas del Diccionario de la RAE. 
- $\quad$ Designación indirecta de la emoción

Esta designación supone dos procedimientos:

(1) Reconstrucción sobre la base de índices lingüísticos, según los estudios de las metáforas emocionales, que permiten reconstruir términos que designan emociones. Así, por ejemplo, si se dice Pedro enrojece, se debe analizar la situación para establecer si enrojece de vergüenza, de cólera, etc. Por convención, para señalar qué se entiende por una emoción reconstruida, se escribirá el término de la emoción entre barras oblicuas / miedo/ vergüenza/, etc.

(2) Reconstrucción sobre la base de lugares comunes situacionales y actitudinales. Aquí es fundamental el principio de que los discursos culturales asocian ciertas emociones a lugares comunes situacionales y actitudinales. Por ello, es posible interpretar enunciados descriptivos de actitud como índices de la emoción sentida por el sujeto. En la medida en que cada emoción corresponde a un componente de "expresión motriz" más o menos convencional en cada cultura, cada hecho es atribuido a un actor y asociado a la emoción correspondiente. Por ejemplo, si el personaje se pregunta: ¿Cómo soportaré la mirada de mis hijos? Se le puede atribuir un sentimiento de /vergüenza/.

A manera de síntesis, la Tabla 1 consigna las emociones según los grados positivo o negativo de las mismas. 
Tabla 1. Grados de evaluación de las emociones.

\begin{tabular}{|l|l|}
\hline Evaluación negativa & Evaluación positiva \\
\hline 1. Tristeza & 1. Felicidad \\
2. Miedo & 2. Sorpresa \\
3. Ira & 3. Agrado \\
4. Sorpresa & 4. Simpatía \\
5. Aversión & 5. Empatía \\
6. Desagrado & 6. Bienestar \\
7. Angustia & 7. Calma \\
8. Vergüenza & 8. Activación \\
9. Celos & 9. Disposición (dispuesto) \\
10. Culpa & 10. Confianza \\
11. Orgullo & 11. Orgullo \\
12. Frustración & \\
13. Molestia & \\
14. Resentimiento & \\
15. Malestar & \\
16. Fatiga & \\
17. Tensión & \\
18. Desconfianza & \\
\hline
\end{tabular}

\section{Resultados}

A continuación nos referiremos a los resultados obtenidos luego que se aplicaran las categorías expuestas en el punto 2. En un primer momento, desplegaremos los resultados obtenidos en cuanto a la caracterización de imágenes; enseguida, las dimensiones discursivas; y, en tercer lugar, presentaremos una síntesis de los aspectos relevantes obtenidos en relación a los topoi, para, finalmente, mostrar el comportamiento de las emociones en los argumentos estudiados.

\subsection{Las imágenes}

Tomando como ejemplo un argumento del programa 'Violencia en los estadios ¿Se perdió la guerra contra las barras bravas?' que forma parte del corpus total, podemos mostrar que: en cuanto al 'nivel plástico', durante la argumentación el enunciador es presentado en primer plano y de fondo se muestra parte del público asistente al programa y a uno de los integrantes de este asintiendo con la cabeza lo expresado por el enunciador. Esto sucede en la mayoría de los 
programas, sin embargo, cabe señalar que durante la investigación, nos encontramos con casos en que los colores fuertes, la sobreexposición de imágenes jugaban un rol importante mientras el enunciador formulaba su argumento. En el 'nivel icónico', resaltan las imágenes de violencia presentadas al terminar la intervención y que muestran enfrentamientos entre barristas y carabineros, destrozos y escenas con alto grado de violencia. Todo este conjunto permite conectar a la audiencia con un imaginario colectivo, vinculado a la violencia y al rechazo que despiertan estas escenas. Cada elemento al que podemos atribuirle una explicación icónica, tiene relación directa o indirecta con las emociones. En cuanto al 'nivel discursivo', corresponde al modo presentativo, en la mayoría de los casos se presenta un elemento aislado, al comienzo de la argumentación, para finalizar con un modo narrativo a través de las imágenes de hechos violentos producidos en el estadio. Finalmente, en el 'nivel simbólico', las imágenes ayudan a crear un imaginario de violencia en los estadios a través de una selección de imágenes de destrozos, enfrentamientos y situaciones que expresan más allá de las palabras los grados de violencia producidas en un espectáculo deportivo, denominado partido de fútbol de alto riesgo.

Si a la categorización de imágenes recién expuesta agregamos la pregunta introductoria, está claro que el desencadenamiento de emociones de carácter negativo será mayor que el de emociones positivas, en consecuencia hay una estrecha relación entre el título del debate, la pregunta introductoria y las imágenes que apoyan esta introducción al tema.

\subsection{Dimensiones discursivas}

Siguiendo con el mismo ejemplo anterior, podemos establecer que en la dimensión textual, el argumento se inicia manifestando (:) simpatía con los vecinos del estadio. La tesis se apoya en ciertos documentos que dan cuenta de las gestiones realizadas por el mismo enunciador anteriormente. En la dimensión interaccional, el panelista plantea su argumento desde lo que él siente, enfatizando con las manos e intentando transmitir un sentido de protección, :- empatía hacia los vecinos para crear un acercamiento mayor con la audiencia y así poder convencer.

\subsection{Tópicos de las emociones}

Los topoi (Plantin, 1998), en el análisis de los argumentos emotivos, permiten desglosar el argumento de acuerdo al evento, sus participantes y cada uno de los elementos involucrados en su configuración para determinar dónde se ubican las emociones y establecer, de este modo, una asociación entre la estructura del argumento y su contenido. El número de argumentos emotivos analizados se relaciona con el programa y el tiempo de cada uno de ellos, según lo expuesto en la Tabla 2. 
Tabla 2. Argumentos emotivos analizados según programa y tiempo.

\begin{tabular}{|l|c|c|}
\hline Programa & Tiempo & Cantidad de argumentos \\
\hline 1. Violencia en los estadios & 35 minutos & 11 \\
\hline 2. Crédito fiscal FF.AA. & 20 minutos & 8 \\
\hline 3. Ley de alcoholes & 40 minutos & 14 \\
\hline 4. Prohibición de marchas & 40 minutos & 8 \\
\hline
\end{tabular}

Podemos concluir que el topoi emotivo más recurrente en este tipo de argumentación es el T8 que corresponde a las consecuencias. Este topoi está relacionado con las predicciones que se pueden desprender de un evento. Proyectar o señalar las consecuencias que se desprenden de un hecho puede desencadenar una serie de emociones y por esta razón se puede explicar que sea el topo recurrente en todos los argumentos emotivos de los cuatro programas analizados. Por ejemplo, en el siguiente argumento extraído del primer programa queda claro lo expuesto:

ARGUMENTADOR 1: yo creo que hay que dar señales de dureza :) TENSIÓN y los dirigentes del fútbol, que son los organizadores del espectáculo, deberían entender $*$ REALIZA GESTOS CON LAS MANOS QUE MANIFIESTAN SU MOLESTIA Y PONEN ÉNFASIS EN SUS PALABRAS que no pueden seguir permitiendo, cobijando a estas barras que lo único que hacen es destruir lo poco que queda de deporte ya en el fútbol. : MOLESTIA-FRUSTRACIÓN.

T8 CONSECUENCIAS: van a destruir lo poco de deporte que queda en el fútbol $:$ MOLESTIA, FRUSTRACIÓN.

Por último, el segundo topoi más usado por los argumentadores es el T1 que se refiere al evento emotivo propiamente tal. El señalar un hecho con toda su carga emotiva es utilizado como una poderosa herramienta para lograr la adhesión de la audiencia, entendiendo que el evento emotivo por sí mismo es capaz de convencer. Ejemplo:

ARGUMENTADOR 2: (primer plano) yo, mano dura *: IRA (GOLPEA LA MESA CON EL CANTO DE LA MANO) nunca más de por vida, es decir, aquí hay que entender que la gente que quiere, que ama el fútbol $:$ AGRADO lo necesita :- EMPATÍA, lo necesita con su familia, con su mujer, con sus hijos, lo necesita. Lo necesita mi escuela de fútbol que tengo de los niños (:) EMPATÍA, BIENESTAR, lo necesita los clubes deportivos de mi comuna, los más modestos, esos necesitan el fútbol, y por eso hay que tener mano dura con esos otros pocos, si no vamos a castigar a muchos por esos otros $:$ MOLESTIA.

T1 QUÉ: Hay que defender al fútbol (-) DISPUESTO para la gente que lo ama :- AGRADO, castigando a los que lo destruyen. 


\subsection{Emociones positivas y negativas}

Las emociones positivas presentes en los argumentos analizados están directamente relacionadas con la complicidad o empatía que el argumentador pretende establecer con la audiencia y con los demás argumentadores, de tal modo que le permita obtener el apoyo y respaldo requerido.

Las emociones negativas, por lo general, se relacionan con un sentimiento de frustración o molestia que se puede explicar de la siguiente manera: al establecer la frustración a través de la presentación de una situación poco alentadora a futuro, se logrará convencer a la audiencia de que ese no es el mejor camino y que debe adherir a la posición de quien argumenta. La molestia e incluso la ira manifestada por los argumentadores se deben a la confrontación lógica del debate. La necesidad de manifestar su oposición a las ideas sostenidas por el otro, en muchas ocasiones se traduce en enunciados cargados de molestia tanto verbal como no verbal.

El Gráfico 1 presenta las emociones de los argumentos analizados del primer programa. Se aprecia claramente un predominio de las emociones de carácter negativo por sobre las de carácter positivo. Molestia, frustración, aversión e ira, son las que presentan los más altos índices de recurrencia, y esto se puede relacionar directamente con el título del debate 'Violencia en los estadios' con evidente carga negativa, al igual que la pregunta introductoria ¿Se perdió la guerra contra las barras bravas?

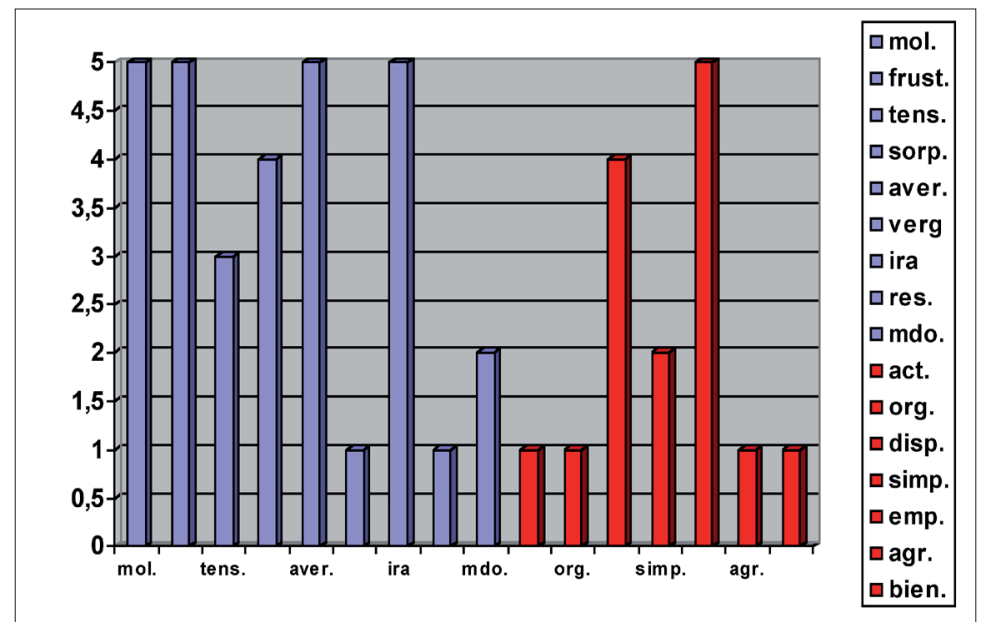

Gráfico 1. Recurrencia de las emociones positivas y negativas en el primer programa. 
Por otra parte, el Gráfico 2 presenta las emociones de los argumentos analizados en el segundo programa. Se aprecia nuevamente una mayor inclinación por las emociones negativas, sin embargo, no se trata de una diferencia tajante. Las emociones negativas más recurrentes son: frustración y molestia, siendo las emociones positivas que destacan: empatía y agrado. Se entiende este comportamiento si consideramos que el título del debate es 'Crédito fiscal FF.AA.', sin presentar ningún tipo de connotación positiva o negativa, como también sucede con la pregunta introductoria ¿Debe el Estado financiar a estudiantes de las FF.AA.?

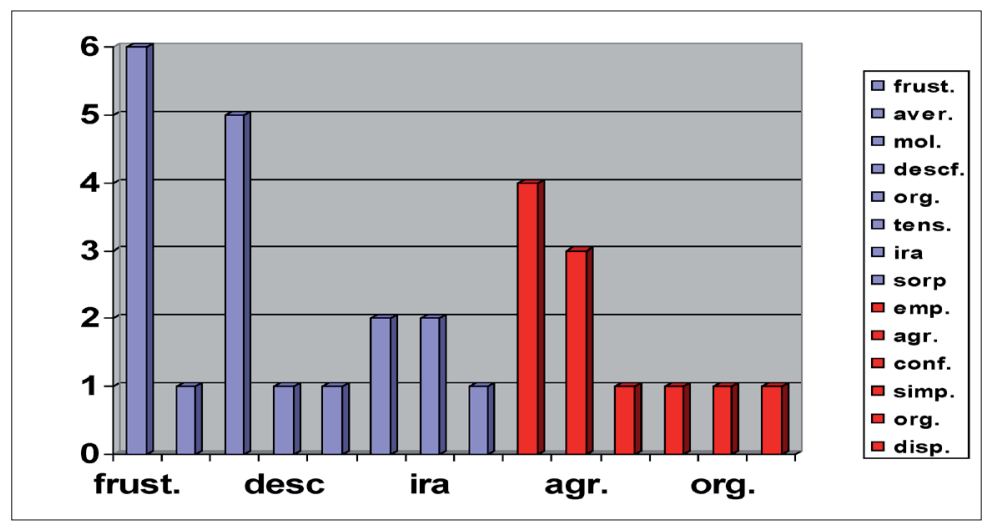

Gráfico 2. Recurrencia de las emociones positivas y negativas en el segundo programa.

Además, el Gráfico 3 presenta las emociones de los argumentos analizados en el tercer programa denominado 'Ley de alcoholes'. Si bien es cierto que el título no posee una connotación negativa, podemos afirmar que la pregunta ‘Protección a los menores o atentado a la bohemia?' y su análisis a partir de su tema y rema, permite establecer una inclinación negativa que justifica la mayor cantidad de emociones de ese carácter. 


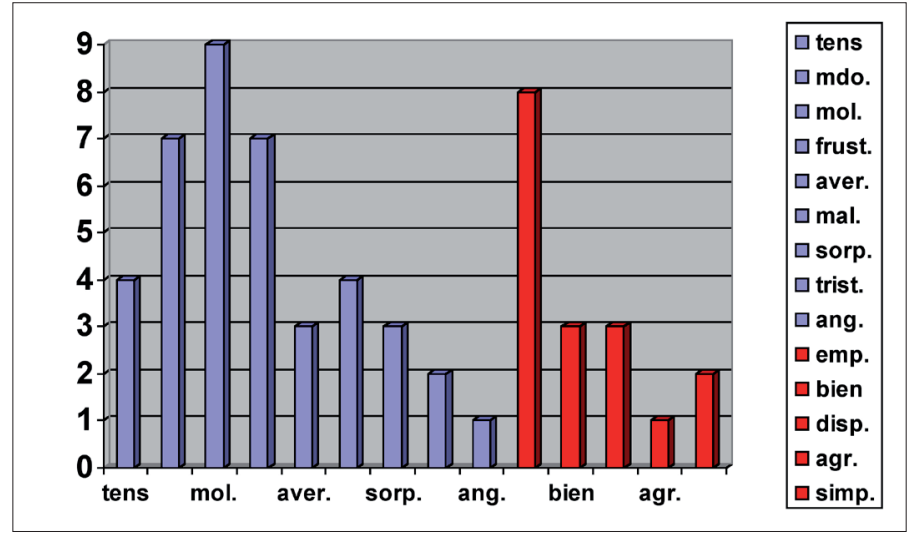

Gráfico 3. Recurrencia de emociones positivas y negativas en el tercer programa.

Finalmente, el Gráfico 4 presenta las emociones de los argumentos analizados en el cuarto programa 'Prohibición de marchas'. En esta interpretación, en particular, debemos decir que a pesar de que el título tiene una connotación negativa a partir del término prohibición, la manifestación de las emociones responde a un contexto mayor; por esta razón no priman las emociones negativas y las que destacan dentro de las emociones positivas son empatía y respeto.

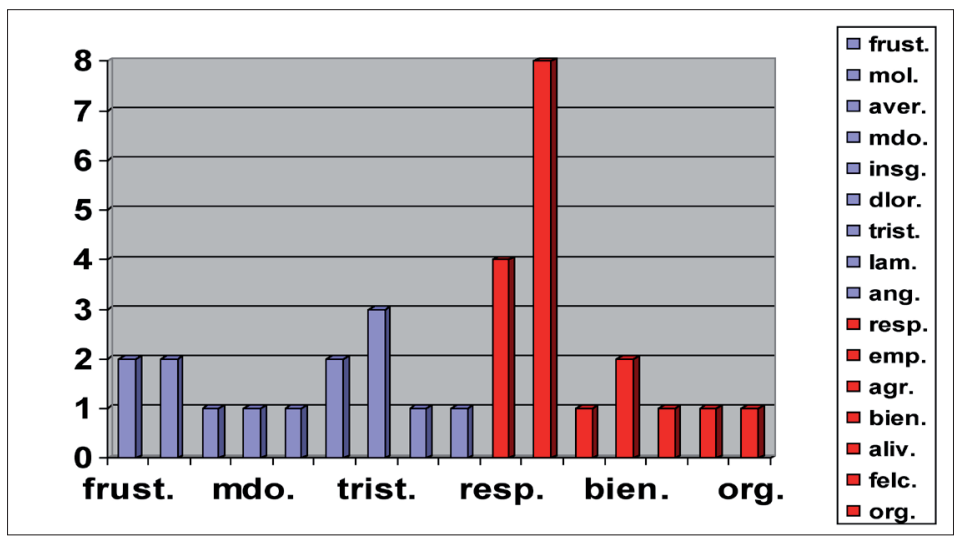

Gráfico 4. Recurrencia de emociones positivas y negativas en el cuarto programa. 


\section{CONCLUSIONES}

La presente investigación significó un aporte al estudio de las emociones en el discurso argumentativo, principalmente porque el corpus elegido corresponde a una argumentación oral, con todo lo que implica el debate televisivo y los enunciadores que lo llevan a cabo. El aporte está en la mirada simultánea que se realiza del discurso argumentativo regulado a través del debate, en la tríada ethos, pathos, logos, poniendo el énfasis en el elemento menos estudiado como es el ámbito de las emociones. Lo interesante es establecer en la dinámica del discurso argumentativo oral el rol que desempeñan las emociones y cómo se pueden clasificar.

Llevar a cabo un trabajo de esta naturaleza significó superar varias etapas complejas que permitieron el avance de la investigación. La primera parte del trabajo práctico consistió en seleccionar el material que conformaría el corpus. Inmediatamente después se procedió a realizar las transcripciones que, a diferencia de otros trabajos en el área lingüística, contemplaban una primera etapa de los enunciados verbales, una segunda fase de lo paraverbal, de lo no verbal y luego todos aquellos elementos propios del programa televisivo, como por ejemplo, la inserción de imágenes, la disposición de las cámaras y los planos en que se presentaba el argumentador.

Cabe destacar que por tratarse de una argumentación oral, no solo las palabras son importantes y juegan un rol al momento de persuadir. Los gestos, el tono y todos aquellos elementos no verbales estudiados y analizados en cada uno de los argumentos, complementaron la carga emotiva propia de cada uno de ellos. El énfasis con que cada enunciador manifestaba su opinión se tradujo en un mecanismo importante de persuasión.

Por otra parte, es importante señalar que la estructura o diseño del programa de televisión que conformó nuestro corpus, es de vital importancia al momento de realizar el análisis. El moderador cuenta con el apoyo de las cámaras de televisión para la organización del debate y la distribución de los turnos. El hecho de que haya una cantidad de imágenes organizadas de modo descriptivo, tomando el concepto propuesto por Soulages (2004), como una introducción al tema, también predispone a la audiencia a un determinado clima emotivo que muchas veces se repite a lo largo del programa, inclinando la opinión de la audiencia hacia un polo determinado.

Otro elemento fundamental es el uso de elementos u objetos emotivos para lograr la adhesión de la audiencia a un argumento en particular: recortes de periódicos, citas de noticias, objetos específicos, etc.

Además, cada uno de los programas analizados contó con un grupo de panelistas distintos que se relacionaban con la temática planteada por alguna afinidad particular. Así, por ejemplo, cuando se trató el problema de la violencia, los panelistas invitados estaban relacionados directamente con el fútbol a través de los equipos involucrados en los clásicos o tenían directa relación con el 
Estadio Monumental, como es el caso del alcalde de Macul, o tenían que ver con seguridad por tratarse del tema de la violencia.

En el programa sobre la prohibición de marchas para el 11 de septiembre en el Cementerio General, estaban invitados solo alcaldes de distintas comunas, siendo quien cumplía un rol protagónico, el alcalde de Recoleta, por ser la comuna en donde se ubica el cementerio. En el programa sobre la ley de alcoholes los invitados eran diputados y senadores para hablar desde su perspectiva sobre este proyecto de ley. También se encontraba invitado como panelista un DJ que podía hablar desde su conocimiento de la bohemia chilena y de lo que podía observar sobre el comportamiento de los jóvenes adolescentes que se involucran a temprana edad con el alcohol y para quienes está dirigida la prohibición del consumo a través de esta ley de alcoholes.

Asimismo, en todos los programas analizados, los panelistas se mantuvieron en su rol sin violar las reglas del debate, y solo llegaron a hablar todos a un tiempo cuando se trataba de defender acaloradamente una idea y se producían otras voces que hacían difícil la comprensión y más aún la transcripción para su posterior análisis.

Cabe recordar que partimos del supuesto de que las emociones que surgen en el discurso argumentativo están íntimamente relacionadas con la temática del discurso. Y, efectivamente, a través de los análisis realizados a los argumentos emotivos, pudimos constatar que las emociones son positivas o negativas de acuerdo a la carga emotiva del tema propuesto a través de una pregunta específica y de un título que permite al moderador guiar a los argumentadores hacia esos polos.

Por otra parte, los topoi propuestos por Plantin (1998) para el análisis de los argumentos emotivos, permitieron desglosar el argumento de acuerdo al evento, sus participantes y cada uno de los elementos involucrados en su configuración para determinar dónde se ubicaban las emociones y permitir establecer una asociación entre la estructura del argumento y su contenido.

En nuestro análisis, percibimos que los argumentadores que en un primer momento nos parecieron coherentes y estructurados en sus planteamientos no lo eran tanto a la hora de desglosar y analizar sus enunciados. Muchas veces nos encontramos con argumentos que partían con una estructura clara y sólida que luego se diluía en otros temas e ideas que no concluían o cerraban la argumentación planteada.

Finalmente, es necesario establecer que investigaciones de esta naturaleza son importantes a la hora de trabajar la argumentación cotidiana y el debate televisivo. Sería interesante, a modo de proyección, plantearse la posibilidad de aplicar otras teorías al análisis, como por ejemplo, la teoría de la valoración desde la Gramática Sistémico Funcional para considerar la intencionalidad en el discurso y las relaciones interpersonales que se desarrollan a lo largo del discurso. 


\section{REFERENCIAS BIBLIOGRÁFICAS}

Calsamiglia, E. \& Tusón, A. (1999). Las cosas del decir. Ariel: España.

Cattani, A. (2003). Los usos de la retórica. Madrid: Alianza.

Charaudeau, P. \& Maingueneau, D. (2002). Dictionnaire d'analyse du discours. Paris: Seuil.

Damasio, A. (1998). The feeling of what happens: Body, emotion and the making of consciousness. New York: Vintage.

Lo Cascio, V. (1998). Gramática de la argumentación. Estrategias y estructuras. Madrid: Alianza.

Lochard, G. \& Soulages, J. (1998). La communication télévisuelle. Paris: Armand Colin.

Perelman, Ch. \& Olbrecht-Tyteca, L. (1989). Tratado de argumentación. La nueva retórica. Madrid: Gredos.

Plantin, Ch. (1989). Argumenter. De la langue de l'argumentation au discours argumenté. Paris: Centre Nacional de Documentation Pédagogique.

Plantin, Ch. (1998). Argumentación. Barcelona: Ariel.

Russell, J., Lewicka, M. \& Niit, T. (1992). A cross cultural study of a circumplex model of affect. Journal of personality and social psychology, 57, 848-856.

Santibáñez, C. (2003). Mirando televisión. Santiago: Bravo y Allende Editores.

Soulages, J. (1999). Les mises en scène visuelles de l'information. Paris: Nathan.

Soulages, J. (2002). Images de citoyens ou paroles de consommateurs: Le talk-show un genre télévisuel postmoderne. French Cultural Studies, 13, 319-336.

Soulages, J. (2004). Los imaginarios socioculturales a través del discurso publicitario. Valparaíso: Pontificia Universidad Católica de Valparaíso.

Ungerer, F. (1995). Emotions and emotional language in English and German news stories. Colloquium on the language of emotions, Duisburg.

Van Eemeren, F. \& Grootendorst, R. (2002). Argumentación, comunicación y falacias: Una perspectiva pragma-dialéctica. Santiago: Universidad Católica de Chile.

Walton, D. (1992). The place of emotions in argument. Pensilvania: University Park. 